\title{
Código da Aliança: o pobre tem vez!
}

\author{
Covenant Code: The poor have a turn!
}

\section{Código de la Alianza: ¡Los pobres tienen un turno!}

\author{
Telmo José Amaral de Figueiredo*
}

\begin{abstract}
RESUMO
O artigo se propõe a investigar, no interior do Código da Aliança (Ex 20,22-23,33), as leis que buscam proteger os mais fracos da sociedade, ou seja, aqueles cujos direitos não são reconhecidos e que estão sujeitos a todos os tipos de arbitrariedades. Portanto, são as normas sociais que estarão mais no foco deste estudo, compreendendo, principalmente o texto de Ex 22,20 a 23,12. O objetivo é realizar um confronto da legislação do Código da Aliança com outros "códigos" legais do Oriente Médio Antigo, justamente a fim de perceber as principais diferenças e características do direito israelita em relação ao de seus vizinhos. Ficará evidente que, apesar de não ser uma legislação que promova uma igualdade social absoluta, as leis israelitas primam por evitar que as camadas mais pobres e frágeis da sociedade sejam, ainda, vítimas da ausência de uma proteção aos seus direitos mais básicos. Além do mais, serão constatados os avanços em relação às demais legislações do Oriente Médio Antigo.
\end{abstract}

Palavras-chave: Código da Aliança; leis; proteção; pobre; Oriente Médio Antigo.

\begin{abstract}
The article intends to investigate, within the Covenant Code (Ex 20,22-23,33), the laws that seek to protect the weakest of society, that is, those whose rights are not recognized and which are subject to all. the types of arbitrariness. Therefore, it is the social norms that will be the focus of this study, comprising mainly the text of Ex 22,20 to 23,12. The objective is to confront the legislation of the Covenant Code with other legal "codes" of the Ancient Near East, precisely in order to understand the main differences and characteristics of Israeli law in relation to those of its neighbors. It will be evident that, although not a legislation that promotes absolute social equality, Israeli laws strive to prevent the poorest and most fragile layers of society from still being victims of the lack of protection of their most basic rights. In addition, progress will be made in relation to the other legislations of the Ancient Near East.

Keywords: Alliance Code; laws; protection; poor; Ancient Near East.

RESUMEN

El artículo pretende investigar, dentro del Código de la Alianza (Ex 20,22-23,33), las leyes que buscan proteger a los más débiles de la sociedad, es decir, aquellos cuyos derechos no son reconocidos y que están sujetos a todos los tipos de arbitrariedad. Por lo tanto, las normas sociales serán el foco de este estudio, que comprende principalmente el texto de Ex 22,20 a 23,12. El objetivo es confrontar la legislación del Código de la Alianza con otros "códigos" legales del antiguo Oriente próximo, precisamente para
\end{abstract}

* Doutor em Letras pela Faculdade de Filosofia, Letras e Ciências Humanas da Universidade de São Paulo (FFLCH/USP) e pós-doutorando em Teologia pela PUC-SP. Membro do Grupo de Pesquisa TIAT - Tradução e Interpretação do Antigo Testamento. 
comprender las principales diferencias y características de la ley israelitas en relación con las de sus vecinos. Será evidente que, aunque no sea una legislación que promueva la igualdad social absoluta, las leyes israelitas se esfuerzan por evitar que las capas más pobres y frágiles de la sociedad sigan siendo víctimas de la falta de protección de sus derechos más básicos. Además, se avanzará en relación con las otras legislaciones del antiguo Oriente próximo.

Palabras clave: Código de Alianza; leyes; protección; pobre; antiguo Oriente Próximo.

\section{Introdução}

Destaquemos o interesse que a Bíblia Hebraica, mais especificamente a Torá, dispensa às leis. Aliás, a própria palavra "Torá" quer significar, não tanto "lei", mas, em linguagem coloquial da época veterotestamentária, o ensinamento da mãe $(\operatorname{Pr} 1,8 ; 6,20$; cf. 31,26) e do pai $(\operatorname{Pr} 4,1-2)$ a fim de introduzir seus filhos no caminho da verdadeira sabedoria, a arte de bem viver. Assim, a palavra "abrange informação e orientação, instrução e estabelecimento de normas, e, com isso, também promessa e desafio" (CRÜSEMANN, 2002, p. 12).

O escopo desse estudo é confrontar o, assim denominado, Código da Aliança (Ex 20,22-23,33) com outros "códigos" legais do Oriente Médio Antigo e verificar se há características próprias de como a Bíblia Hebraica $(\mathrm{BH})$ trata a pessoa mais frágil da comunidade, o pobre, em relação às demais pessoas na sociedade. Para isso, analisaremos alguns dos textos mais específicos sobre a questão do pobre. Referimo-nos, aqui, ao conjunto de leis presente em Ex 22,20-23,12.

No entanto, se faz mister iniciarmos esse estudo aclarando algumas questões de ordem literária, histórica e social.

\section{O Código da Aliança: seu lugar em Êxodo}

O nome para esse conjunto legal provém de sua inserção em meio à narrativa da aliança concluída entre o Senhor e Israel no Sinai (Ex 19-24), como aparece em Ex 24,7: livro da Aliança (sëper habb rît). No interior do livro do Êxodo, encontramos quatro conjuntos legislativos que parece interromperem o fio narrativo no qual o livro está emoldurado, mas que fazem parte do estilo legal da $\mathrm{BH}$, a legislação. Vejamos:

a) Leis sobre a páscoa, os ázimos e os primogênitos: Ex 12-13;

b) Decálogo: Ex 20;

c) "Código da Aliança": Ex 20,22-23,33

d) o código ritual (decálogo cultual) (ZENGER, 2008, p. 128-130): Ex 34,14-26. 
Seguindo a proposta de Wiéner (WIÉNER, 2000, p. 12), o "código" é localizado no centro do livro, como pode-se constatar na estrutura a seguir:

I. A LIBERTAÇÃO ANUNCIADA $(1,1-6,27)$

A opressão no Egito: primeiros passos de Moisés.

II. A LIBERTAÇÃO RETARDADA $(6,28-11,10)$

As pragas do Egito; a negativa do faraó.

III. A LIBERTAÇÃO REALIZADA (12,1-16,36)

A última praga

12,1-13,22: leis sobre a páscoa, os ázimos, os primogênitos

A partida: o milagre do mar

IV. A ALIANÇA DO SINAI (17,1-24,11)

$O$ grande encontro com Deus

20,1-17: o decálogo

20,22-23,33: o código da aliança

A conclusão da aliança

V. A ADORAÇÃO ANUNCIADA (24,12-31)

O projeto do santuário revelado a Moisés

VI. A ADORAÇÃO RETARDADA (32,1-34,35)

A crise do bezerro de ouro: a reconciliação

34,14-26: código ritual / cultual

VII. A ADORAÇÃO REALIZADA $(35,1-40,38)$

O santuário construído com entusiasmo e consagrado pela presença divina.

O Código da Aliança apresenta-se como um desenvolvimento do decálogo, promulgado, segundo a tradição judaica, por Moisés. Observamos que toda a redação do Código da Aliança "é dominada pelo $1^{\circ}$ mandamento, respectivamente pelo $2^{\circ}$ mandamento $(20,23 ; 22,19 ; 23,13.24 .32 \mathrm{~s})$. Esta composição se destaca como fala de Deus, que foi dada a Israel no Sinai através da mediação de Moisés" (CRÜSEMANN, 2002, p. 160.

Inspirando-nos em L. Schwienhorst-Schönberger (ZENGER, 2008, p. 279), pode-se propor a seguinte estruturação desse código. Interessante observar, nessa estruturação, que o título (Ex 21,1) não inicia o bloco narrativo, assim como o enunciado final $($ Ex 23,13) não representa exatamente a conclusão o código. Isso indica um longo processo de surgimento. Vejamos, então, essa estrutura: 


\begin{tabular}{|ll|}
\hline $20,22 \alpha$ & Introdução do discurso \\
$20,22 \alpha \beta$ & Encargo de falar aos israelitas \\
\hline
\end{tabular}

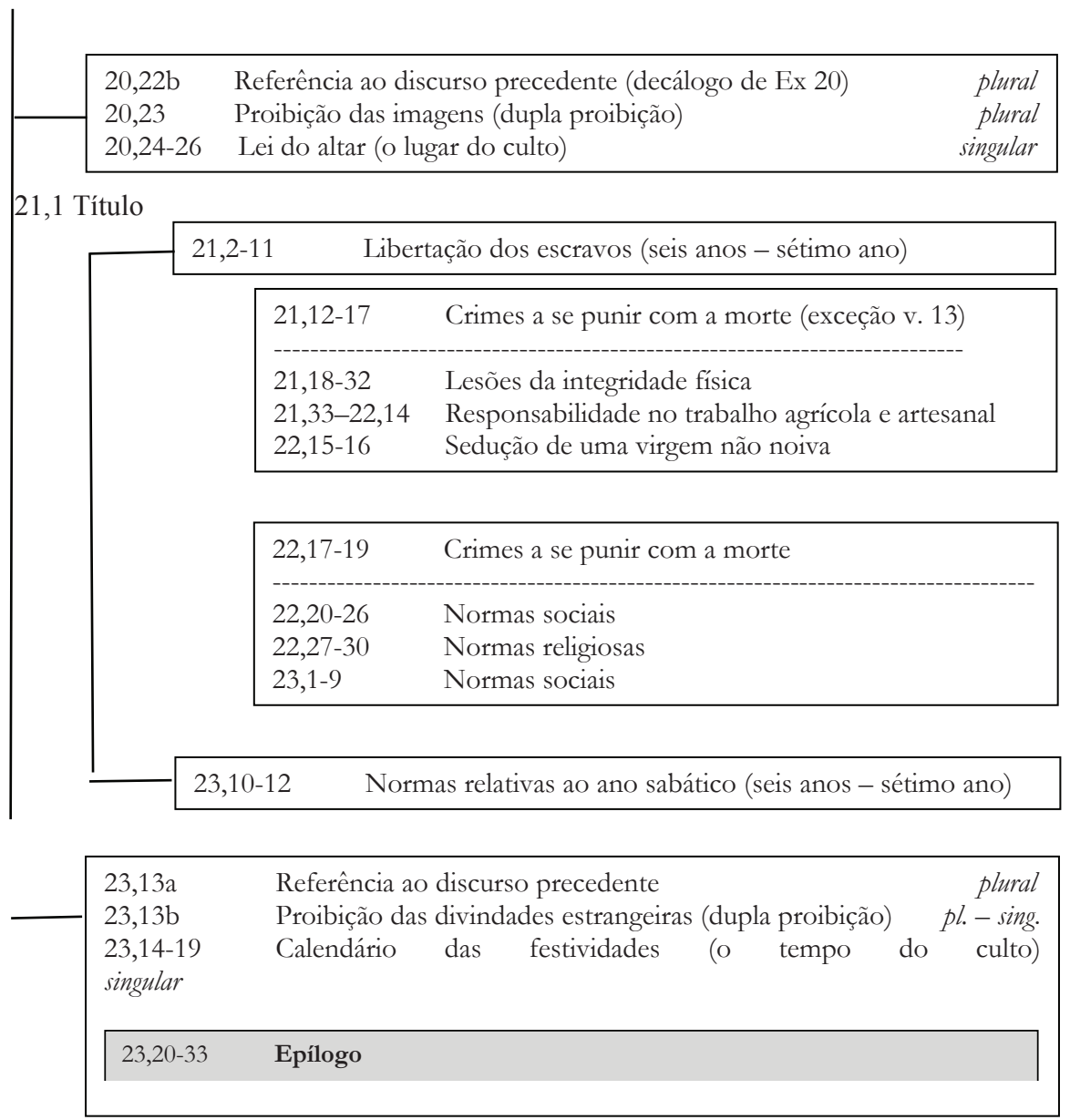

Percebe-se que o Código da Aliança encontra-se bem enquadrado por Ex 20,22-23 e 23,20-33. Halbe (1975, p. 416-418, 421) postulava que Ex 22,19 ("Quem sacrificar a deuses, a não ser só a YHWH, será exterminado" ${ }^{1}$ representava o centro do Código da Aliança, fazendo parte do segundo bloco de "crimes a se punir com a morte". A maioria dos estudiosos reconhece que toda essa sessão é fruto de um processo de acréscimos sucessivos. Sendo que, Ex 21,12-22,16, do ponto de vista histórico e literário, constituiria a forma mais antiga desta coleção jurídica

\footnotetext{
Tradução própria.
} 
(HALBE, 1975, p. 279). O estilo dessa parte mais antiga do Código da Aliança é de um código casuístico. Seu Sitz im Leben seria o contexto da administração da justiça e da erudição jurídica. Contudo, não se trataria de ver nessas definições de casos e determinações da consequência jurídica, um código que nos levasse ao estilo de administração da justiça aplicada às portas da cidade, como de praxe na antiguidade. Tratar-se-ia, sobretudo, na hipótese de L. Schwienhorst-Schönberger, de uma "erudição especificamente jurídica, a qual deveria ter o seu lugar institucional em uma espécie de escola de escribas". ${ }^{2}$ Essas escolas, comuns no Oriente Médio Antigo, eram o lugar em que se conservavam e transmitiam literariamente a cultura jurídica. Por isso, não é de se estranhar a semelhança do Código da Aliança com outros "códigos" ou tratados jurídicos daquela região.

A fim de evitar o crescimento infinito de um código casuístico, era praxe nas escolas de escribas as técnicas de inclusão e atração. Uma norma introduzida a respeito de um caso poderia ser aplicada a outros casos semelhantes, não necessariamente descritos naquele código. Devido a isso, podemos supor, com grande margem de segurança, que o modelo se "suplemento" deve ter funcionado no caso do Código da Aliança. Um texto fundamental (Ex 21,12-22,16 primitivo) foi sendo, paulatinamente, ampliado com outras normas jurídicas. ${ }^{3}$

\section{Código da Aliança: seu contexto histórico}

Obviamente, é muito difícil precisar uma época determinada para a origem de nosso código. No entanto, é comum datá-lo do final do século VIII ou do início do século VII a.C. conforme amplo consenso (ARTUS, 2005, p. 61). Algo de semelhante à pregação profética que se desenvolveu nos reinos do Norte e do Sul no VIII século a.C. pode-se reencontrar nesse conjunto de leis (cf. Am 2,6-16 e Is 1,16-17), sendo que ele reuniria tradições antigas, pré-monárquicas, pré-deuteronômicas. A origem dessas leis remonta, certamente, à uma época bem antiga, refletindo uma sociedade pouco estruturada, rural, mais centrada na criação de gado que na agricultura. Depreende-se disso que as pessoas dispõem de poucos recursos e a família e a casa parecem ser as estruturas essenciais. O conjunto de normas presente em Ex 21,28-22,14 nos revela esse ambiente pastoril:

2 Das Bundesbuch (Ex 20,22-23,33). Studien zu seiner Entstehung und Theologie. Apud ZENGER, 2008, p. 280-281.

3 Para uma abordagem mais exaustiva dessa temática, consultar: LASSERRE, 1993, p. 267-276. 
a) Ex 21,28-36: trata dos acidentes causados por bois;

b) Ex 21,37-22,8: aborda o furto de um boi ou ovelha;

c) Ex 22,9-14: fala do empréstimo ou guarda de um animal (VERKINDÈRE, 1998, p. 7).

De todo modo, não se trata de uma sociedade nômade, mas sedentarizada ou semisedentária.

[...] o povo tem seus responsáveis, porém não se fala do rei; existe uma organização da justiça e do culto, porém não se menciona sacerdotes especializados; celebram-se festas e as peregrinações estão ligadas às etapas da vida rural, porém também à recordação da saída do Egito (WIÉNER, 2000, p. 38-39).

Na expressão assumida por Zenger (2008, p. 281), essas leis, ao serem incorporadas no contexto de uma redação mais ampla, a aliança do Sinai $(17,1-24,11)$, foram teologizadas. Ou seja, ampliadas com diretrizes jurídicas sociais e sacrais, como discurso de Deus. Poderia se tratar do...

[...] programa de sacerdotes de Jerusalém para renovar a coesão e a solidariedade da sociedade judaíta que estava se rompendo nos conflitos sociais. Sua pretensão era de que Deus estava manifestando sua vontade acerca da prática do direito e da justiça no sentido de uma solidariedade com os fracos da sociedade. [...] O pano de fundo são os conflitos sociais na Judá do fim da monarquia, que aumentaram desde o século VIII e motivaram os autores do Código da Aliança a redigir uma ordem legal legitimada pela declaração de que ela provinha da vontade de Deus (OTTO, 2011, p. 124-125, 126).

Podemos assumir que, com o Código da Aliança, "começa a história literária do direito bíblico" (OTTO, 2011, p. 125). Ao incorporar essas normas à experiência da libertação da escravidão no Egito, tem-se em vista "a convicção de que as leis aqui reunidas são condizentes com o projeto do êxodo... a intenção é transformar a experiência histórico-religiosa da libertação em um projeto jurídico que, por sua vez, quer servir à construção de uma sociedade alternativa" (GRENZER, 2004, p. 140-141).

\section{Código da Aliança: sua finalidade}

Importante localizar o Código da Aliança no interior de Ex 19-24, justamente a conclusão da aliança de YHWH no Sinai e a construção do santuário - a instituição mais representativa. Ele foi colocado aí com uma intenção, ou seja, fazer com que o Código da Aliança estivesse sob a au- 
toridade de YHWH, no contexto da teofania do Sinai. Desse modo, essas leis se tornam leis divinas com todas as consequências daí decorrentes.

Ligadas a essa manifestação divina no Sinai, as leis desse código "traçavam, de algum modo, a reposta que YHWH esperava de Israel, enquanto povo engajado na aliança. Esse código definia a maneira de viver que envolvia esta relação com Deus e apresentava as exigências impostas àquele que deveria tornar-se o povo eleito" (RENAUD, 2008, p. 41). Portanto, sua finalidade é a mesma do decálogo. Ambos fazem referência à saída do Egito e a marcha pelo deserto (cf. Ex 20,2, de modo explícito, e 20,22, de modo implícito: "Vós tendes visto que eu falei convosco desde os céus"), os quais possuem um valor teológico de "atos de eleição" (RENAUD, 2008, p. 41). A aliança no Sinai não possui, somente, implicações espirituais e cultuais, mas, especialmente, morais para o "povo eleito".

\section{O Código da Aliança no contexto jurídico do Oriente Médio Antigo}

Temos o registro de normas jurídicas desde o final do terceiro ao início do segundo milênio a.C. na antiga Mesopotâmia. A Assíria, a Acádia, a Suméria e a própria Babilônia (na qual os territórios da Acádia e da Suméria se juntaram) apresentam coletâneas de leis desse período. Os exemplos mais significativos e conhecidos são (cf. VERKINDÈRE, 1998, p. 10-11; SKA, 2006, p. 23):

a) As leis de Ur-Nammu ou Ur-Namma (2111-2094 a.C.): rei sumério fundador da terceira dinastia de Ur, cidade ao sul da Mesopotâmia. Alguns atribuem esse conjunto legal ao seu filho, Shulgi. Trata-se do mais antigo "código" descoberto até agora.

b) Leis de Lipit-Ishtar (1934-1924 a.C.): da dinastia Isin, atualmente Ishan Bahriyat, na região de Diwanyé, ao sul do atual Iraque.

c) Leis de Eshnunna (1825-1787 a.C.): descobertas em Tell Abu Harmal, pequena localidade ao sul de Bagdá, no Iraque. ${ }^{4}$ São do reinado de Bilalama.

d) Leis de Hammurabi (1792-1750 a.C.): descobertas durante as escavações realizadas na acrópole da capital elamita de Susa, no inverno de 1901-1902. Essa localidade situa-se no atual Irã, cerca de 250 quilômetros ao norte do porto petrolífero de Abadan. ${ }^{5}$

4 Para detalhes sobre o contexto histórico e social do surgimento dessas leis, cf.: HAMMURABI, 1976, p. 13-51.

5 Detalhes da localidade, da história da descoberta e da região na Antiguidade, cf.: HAMMURABI, 1976, p. 9-18. 
e) Édito de Ami-Saduca (1646-1626 a.C.): foi o décimo rei da dinastia de Hammurabi (Babilônia). Esse documento traz, de modo completo, a proclamação que os reis dessa época realizavam no início de seu reinado e em intervalos, provavelmente, a cada sete anos. Nessa proclamação o rei anunciava a "remissão das dívidas e a devolução das terras aos proprietários que as haviam cedido aos seus credores para o pagamento de dívidas. A 'lei do jubileu' de Lv 25 inspira-se mais que provavelmente nesse costume" (SKA, 2006, p. 23, n. 19).

f) Compêndio de leis assírias (1114-1076 a.C.): uma compilação realizada sob o reinado de Teglat-Falassar I. Essas leis foram descobertas em Assur, antiga capital da Assíria, atualmente Qal'at Shirqat, a 112 quilômetros ao sul de Mossul, Iraque.

g) Leis hititas (da metade do séc. XVII ao início do séc. XII a.C.): trata-se de um império que se desenvolveu na região da Anatólia, especialmente do século XV ao XIII a.C. As tabuletas com as leis foram encontradas em Hatusa, a capital dos hititas, atualmente Boghazkoy, no centro da Turquia.

A característica comum a todos esses conjuntos legais, é que se trata, sobretudo, de um direito consuetudinário, o qual ultrapassava todas as fronteiras e limites de povos da época. Esses conjuntos de leis não se parecem tanto a um código, mas emendas ao direito comum, ao direito que surge a partir dos costumes dos povos. Trata-se de leis mais descritivas que prescritivas.

Em geral, a justiça (no código de Hammurabi, em acádio: $m i-s ̌ a-r a-$ am) tem como propósito evitar que o mais forte, o rico, oprima o pobre ou leve algum tipo de vantagem sobre este. E o meio mais empregado para coibir esse abuso é a ameaça de uma violenta desforra dirigida aos que se aproveitam da fraqueza da pessoa mais humilde. No entanto, ao analisar tais "códigos" legais, não se pode, ainda, perceber neles a busca de uma "justiça social", apesar do conceito não estar totalmente fora de lugar. $\mathrm{Na}$ região do assim chamado Crescente Fértil, como vem conhecido o Oriente Médio Antigo, a justiça social era concebida da seguinte forma:

[...] como uma proteção dos fracos, para impedir que fossem destituídos injustamente do que lhes era devido, ou seja, a posição social legal, os direitos de propriedade e a condição econômica a que tinham direito em virtude da posição que ocupavam na hierarquia existente. Nada indica que os direitos ou a condição dos fracos devesse ser igual ou comparável à dos outros de posição social superior na sociedade (JOHNSTON, 2018, p. 19). 
Portanto, nessas sociedades, o aristocrata não tinha o direito de agir impunemente contra uma pessoa de posição social inferior, devido ao fato dela também ter direitos. No entanto, a punição pela violação do direito do mais fraco não se comparava àquela contra alguém que violasse o direito de alguém em posição social mais elevada. Somente a título de exemplo, vejamos algumas leis presentes no código de Hammurabi a esse respeito:

$\S$ 196: Se um awīlum destruiu o olho de um (outro) awīlum|: destruirão o seu olho. $\S$ 197: Se quebrou o osso de um awīlum: quebrarão o seu osso.

§ 198: Se destruiu o olho de um muškênum ou quebrou o osso de um muškênum: pesará uma mina de prata (HAMMURABI, 1976, p. 87).

O awīlum era o homem livre, cidadão com plenos direitos, pertencente a uma categoria social superior. O muškênum era alguém pertencente a uma classe social inferior, essa palavra encontra-se em etíope e árabe, p. ex., como significando o "pobre" (HAMMURABI, 1976, p. 16, n. 42). Repare-se que, quando o agressor e o agredido pertencem à mesma classe social, no caso um awīlum, a punição segue a lei de talião - olho por olho, dente por dente -, quando são de classes sociais diferentes, ou seja, o agressor é um awīlum, mas o agredido é um muškênum, então a pena é mais branda, no caso, uma multa de 500 gramas, aproximadamente, de prata. Interessante observar que, também, na $\mathrm{BH}$ encontramos algo semelhante: Ex 21,23-25 (Código da Aliança); Lv 24,19-20 (Lei de Santidade) e Dt 19,21 (Código Deuteronômico).

Restando, ainda, ao código de Hammurabi, percebe-se um endosso às diferenças hierárquicas na sociedade, em uma escala que vai do mais alto ao mais baixo, como se nota em um outro exemplo:

$\S 8$ : Se um awīlum roubou um boi ou uma ovelha ou um asno ou um porco ou uma barca: se é de um deus ou do palácio deverá pagar até trinta vezes mais; se é de um muškênum restituirá até dez vezes mais. Se o ladrão não tem com que restituir, será morto (HAMMURABI, 1976, p. 27).

Resumindo, no direito babilônico, assim como nos demais do Oriente Médio Antigo, "as penalidades pela violação dos direitos de outra pessoa (ou instituição) variam enormemente de acordo com a posição social tanto da vítima do delito como do transgressor" (JOHNSTON, 2018, p. 20). O direito é do tipo retributivo: a punição é proporcional ao delito cometido, abusando muito de altas multas, mutilação e morte. Ou seja, de acordo com esses "códigos" legais, faz-se justiça quando "a vingança é infligida sobre os transgressores" (JOHNSTON, 2018, p. 26). 
Com relação ao direito hebraico, percebe-se algumas características semelhantes aos demais conjuntos legais do Oriente Médio Antigo, porém com algumas importantes nuanças. Vejamos:

a) Enquanto que, p. ex., no código de Hammurabi, em seu epílogo, os sucessores desse rei são estimulados a preservar a lei e a proteção aos mais fracos (16 versos destacam a prosperidade dos governantes que assim agirem), outros 280 versos ameaçam com terríveis consequências o governante que não executar as leis de Hammurabi (HAMMURABI, 1976, p. 109-114). Para a BH, os deveres para com os pobres e os fracos são deveres de justiça e não de caridade. Muitas das passagens que evocam esses direitos o fazem utilizando o termo hebraico para justiça mišpa $\bar{a} .{ }^{6}$

b) Ao contrário das leis mesopotâmicas, as hebraicas não conhecem uma aristocracia com privilégios legais, para a qual as penas são mais brandas do que para os mais pobres e humildes. Não há, então, punições diferenciadas para categorias diferentes de vítimas ou perpetradores. Como deixa explícito Ex 21,23-25: "Mas se houver algum dano grave, então, darás vida por vida olho por olho, dente por dente, pé por pé, queimadura por queimadura, ferida por ferida, golpe por golpe". ${ }^{7}$ Portanto, entre adultos do sexo masculino havia uma igualdade maior, ao menos legal, do que na cultura mesopotâmica. No entanto, os escravos eram tratados uma pouco diversamente: "Se alguém ferir o olho do seu escravo ou o olho da sua serva, e o inutilizar, deixá-lo-á livre pelo seu olho" (Ex 21,16; cf. 21,27). Portanto, no caso de um dano ao escravo, não se perdia o próprio olho como penalidade, mas se concedia a alforria.

c) As penas são mais proporcionais aos delitos cometidos. Somente a título de exemplo, pode-se citar: "Se alguém roubar um boi ou uma ovelha e o abater ou vender, restituirá cinco bois por um boi e quatro ovelhas por uma ovelha. [...] o ladrão fará restituição total. Se não tiver com que pagar, será vendido por seu furto. Se o animal roubado, boi, jumento ou ovelha, for encontrado vivo em seu poder, restituirá o dobro" (Ex 21,37; 22,2b-3). É suficiente comparar com o $\S 8$ do código de Hammurabi, citado acima, para se perceber o exagero da pena aplicado por ele em um delito semelhante.

Cf. p. ex.: Ex 23,6; Dt 10,18; 16,9; Is 1,17.

7 Textos bíblicos, exceto menção em contrário, são extraídos da Bíblia DE JERUSALÉm. 
Contudo, não se pode afirmar, em relação ao direito hebraico, que se trate de um código que regula uma sociedade igualitária. Pelo contrário, há uma conformidade com a hierarquia social existente onde as diferenças sociais eram toleradas e consideradas normais.

\section{Especificidades do direito bíblico, incluso o Código da Aliança}

Antes de adentrarmos em aspectos particulares das leis sobre o direito do pobre no interior do Código da Aliança, é importante salientar algumas características próprias do direito bíblico, que o diferencia de outros conjuntos legais do Oriente Médio Antigo (cf. SKA, 2006, p. 34-46).

\section{O legislador de Israel é Moisés}

Nenhum dos códigos da BH são atribuídos a um rei. Moisés, curiosamente, é situado no período pré-monárquico. Desse modo, a lei de Israel não vem unida à monarquia, como em todos os demais povos daquela época. Aliás, o próprio rei está submetido à lei (cf. Dt 17,18-19). O único caso em que um rei parece promulgar uma lei, Josias (em Judá, 2Rs 22) é muito discutido. Inclusive, porque a lei "encontrada" no Templo jamais vem denominada de "lei de Josias". A autoridade de Moisés "não é de ordem política ou econômica. [...] Sua autoridade define-se mais em termos de 'conhecimento': YHWH conhecia Moisés face a face (Dt 34,10)" (SKA, 2006, p. 41; cf. Nm 12,6-8). Ele é um profeta, portanto, membro da corte celeste, ${ }^{8}$ o que lhe permite conhecer os desígnios de Deus, segundo tradição expressa em Ex 3,1-4,20; Dt 34,10-12.

\section{Uma lei para um povo sem território}

A lei de Moisés é proclamada, segundo a narrativa bíblica, no deserto, antes da entrada do povo na Terra Prometida. Ocorre, como salienta Ska, que "Rei (ou autoridade legítima) e território são os dois pilares do direito antigo e moderno". Portanto, a lei israelita é uma raríssima exceção. Israel, ao receber sua lei de Moisés, não está em um território seu, mas em uma “terra de ninguém" (SKA, 2006, p. 34). Essa realidade corresponde ao período pós-exílico, no qual o povo "pode se reconstruir após a monarquia e sem a monarquia porque é mais antigo que a monarquia e mais antigo que a entrada na terra. Aquilo que pode existir antes da monarquia pode também existir após seu desaparecimento" (SKA, 2006, p. 35).

$8 \quad$ Cf. Jr 23,18.22; Am 3,7; 1Rs 22,19-22. 
No entanto, a originalidade não se encontra nesse fato, pois também é a divindade babilônica que confia a lei a Hammurabi. ${ }^{10}$ Como assinala Ska, na Bíblia "a autoridade divina não é do mesmo tipo que a autoridade humana [...]. Ser responsável perante Deus é ser responsável perante 'ninguém'. O estudo do direito em Israel une-se aqui à mística" (2006, p. 35-36). E esse Deus não pode ser representado por forma alguma deste mundo, desse modo, “encontrar-se responsável perante Deus significa, portanto, encontrar-se diante de uma espécie de 'vazio' jurídico que se assemelha ao 'deserto' no qual é proclamado o direito de Israel” (SKA, 2006, p. 36).

\section{Um direito que apela à consciência coletiva e individual}

Como consequência do afirmado no item anterior, "o povo é confrontado com sua própria responsabilidade. [...] O direito de Israel não será 'territorial', como tantos outros direitos, ele será antes de tudo 'pessoal"' (SKA, 2006, p. 36). Mais, ainda, esse direito não pode ser imposto pela força, mas receber o consentimento do povo no contexto de uma aliança entre Deus e o povo (cf. Ex 19,8; 24,3.7). Afinal, Israel é livre, está fora do domínio do faraó. Sendo Deus o único soberano, todos são iguais perante essa lei. Não há espaço para uma relação do tipo "governantes" e "governados". O poder não se encontra nos seres humanos, mas em Deus. O destino e a sobrevivência do povo estão nas próprias mãos dele. Por isso, ele pode e deve repensar seu direito para sobreviver entre as nações. Na prática, porém, como algumas leis são transmitidas ao povo por Moisés (cf. Ex 20,18-22; Dt 5,23-30; 6,1-2), isso acaba introduzindo um elemento humano nesse processo, permitindo ajustamentos posteriores. Assim postula Ska: "Quem pode reivindicar uma autoridade semelhante à de Moisés pode também interpretar e adaptar a lei. Estes são, durante o período pós-exílico, as famílias sacerdotais e anciãos" (2006, p. 37). ${ }^{11}$

9 Cf. uma longa tratativa desse tema em: OOSTHUIZEN, 1996, p. 160-190.

10 HAMMURABI, 1976, p. 24: "Quando o deus Marduk encarregou-me de fazer justiça aos povos, de ensinar o bom caminho ao país, eu estabeleci a verdade e o direito na linguagem do país, eu promovi o bem-estar do povo".

11 A legitimação dos anciãos como herdeiros da tradição de Moisés aparece em Nm 11,130, especificamente, nos vv. 11-17 e 24-25. 
O estilo das leis bíblicas é mais o de uma homilia, uma exortação moral do que um conjunto de normas frias, escritas em um vocabulário mais jurídico. Ao invés de sanções previstas para os delitos, encontramos parêneses e justificativas. O Código da Aliança contém vários exemplos nesse sentido: Ex 22,20.25-26; 23,4.8.

\section{O direito do pobre no Código da Aliança $(E x$ 22,20-23,12)}

O conjunto de leis apodíticas presentes em Ex 22,20 a 23,12, distingue-se bem do material anterior, inclusive pela linguagem, além da casuística presente no bloco anterior. Não comparece, nesse bloco, sanções e a parenética domina na apresentação das leis. Em Ex 22,20-26, "se", "pois" (heb.: kî) e "caso" ('im) são empregados de modo diferente (CRÜSEMANN, 2002, p. 211):

a) Importantes regras são introduzidas através de "caso" ('im - Ex $22,22.24 .25)$

b) enquanto que nas frases de fundamentação utiliza-se "se" ( $k \bar{l}-\mathrm{Ex}$ 22,20.22.26a.b).

Esse conjunto apodítico enfoca como os dois principais problemas sociais o estrangeiro e o pobre. Sendo que, o tema do estrangeiro ( $g \bar{e} r$ ) forma uma moldura literária: Ex 22,20a e 23,9.

Façamos um confronto sinótico entre as normas presentes nesse bloco do Código da Aliança e os demais conjuntos legais do Oriente Médio Antigo. (Veja na página seguinte)

\section{Leis sobre o estrangeiro}

Primeiramente, cabe frisar que se entende pela categoria de gēr (em hebraico), o imigrante, o estrangeiro, que reside no país, portanto, aquele que tem uma estabilidade, não o que passa por uma terra estrangeira (heb.: nokrī, o "estranho", Gn 31,15). O gēr é aceito pela população e goza de certos direitos; não se identifica com o(a) escravo(a). No entanto, "ele não tem direito à posse de terra, de um domínio. Assim será durante todo o tempo da monarquia" (VERKINDÈRE, 1998, p. 12). Eles, também, não podiam ser ouvidos em um processo à porta das cidades, como era costume na época. Portanto, é devido a isso que o imigrante é mantido em uma situação de indigência, dependendo constantemente do autóctone. 


\begin{tabular}{|c|c|}
\hline Código da Aliança ${ }^{\mathrm{I}}$ & Leis Mesopotâmicas \\
\hline $\begin{array}{l}\text { O estrangeiro }(g \bar{e} r) \\
{ }^{22,20} \text { O estrangeiro não afligirás, nem o } \\
\text { oprimirás; pois fostes estrangeiros na } \\
\text { terra do Egito. [...] } \\
23,9 \text { Vós, também, não oprimirás o } \\
\text { estrangeiro; pois vós conheceis o coração } \\
\text { do estrangeiro, porque fostes estrangeiros } \\
\text { na terra do Egito. }\end{array}$ & \\
\hline $\begin{array}{l}\text { A viúva e o órfão ('almänâ, yätôm) } \\
22,21 \text { A nenhuma viúva nem órfão } \\
\text { afligireis. } \\
{ }_{22,22} \text { Caso de algum modo os afligires, } \\
\text { e eles clamarem a mim, eu certamente } \\
\text { ouvirei o seu clamor. } \\
22,23 \text { E a minha ira se acenderá, e vos } \\
\text { matarei à espada; e vossas mulheres } \\
\text { ficarão viúvas, e vossos filhos órfãos. }\end{array}$ & $\begin{array}{l}\text { A viúva e o órfão } \\
\text { Uru-inimgina fez um pacto com o divino Nin-Girsu de que o homem poderoso } \\
\text { não iria oprimir o órfão (ou) a viúva (HALLO; YOUNGER JR., 2003, p. 408). }{ }^{\mathrm{II}} \\
\text { Linhas 162-168: Não entreguei o órfão aos ricos. Não entreguei a viúva ao poderoso. } \\
\text { Não entreguei o homem com apenas um siclo ao homem com uma mina (ou seja, } \\
60 \text { siclos). Não entreguei o homem com apenas uma ovelha ao homem com um } \\
\text { boi (HALLO; YOUNGER JR., 2003, p. 409).II } \\
\text { § 177: Se uma viúva, cujos filhos são pequenos, decidiu entrar na casa de um outro } \\
\text { [casar-se novamente], não poderá entrar sem a permissão dos juízes. Quando ela for } \\
\text { entrar na casa de um outro, os juízes examinarão a situação da casa do seu primeiro } \\
\text { marido e confiarão a casa de seu primeiro marido ao seu segundo marido e à mulher } \\
\text { e lhes farão redigir uma tábua. Eles guardarão a casa, criarão os filhos pequenos e } \\
\text { não venderão os objetos. O comprador que comprar os objetos dos filhos de uma } \\
\text { viúva perderá a sua prata; os bens voltarão ao seu proprietário. } \\
\text { Epilogo 60: Para que o forte não oprima o fraco, para fazer justiça ao órfão e à } \\
\text { viúva [...] (HAMMURABI, 1976, p. 79-80, 109). }\end{array}$ \\
\hline $\begin{array}{l}\text { Empréstimo a juros (nešek) } \\
{ }^{22,24} \text { Caso emprestares dinheiro ao meu } \\
\text { povo, ao pobre que está contigo, não te } \\
\text { agirás com ele como um usurário; não } \\
\text { lhe imporeis usura. }\end{array}$ & $\begin{array}{l}\text { Empréstimos a juros } \\
\text { § L: Se um mercador emprestou grão com juros: ele tomará por } 1 \text { GUR de grão... } \\
\text { juros. Se ele emprestou prata com juros: ele tomará por um siclo de prata como juros } \\
1 / 6 \text { de siclo e seis grãos. } \\
\text { § M: Se um awĩlum, que tem uma dívida, não tem prata para restituir, mas tem } \\
\text { grão: o mercador tomará como juros o correspondente em grão de acordo com as } \\
\text { prescrições do rei. Se o mercador exigiu como juros mais do que... por } 1 \text { GUR de } \\
\text { grão ou 1/6 de siclo e } 6 \text { grãos [por um siclo de prata] perderá tudo o que emprestou } \\
\text { IV (HAMMURABI, 1976, p. } 49 \text { ). } \\
\text { § 18a: Por um siclo (de prata) ele deverá acrescentar um sexto de siclo e seis } \breve{S} E \\
\text { como juros; por um } G U R \text { (de cevada) ele deverá acrescentar um (pan e) quatro } \\
\text { sat de cevada como juros. } \\
\text { § 20: Se um awīlum deu... para... mas converteu a cevada em prata: na colheita } \\
\text { ele tomará a cevada e os seus juros: por um GUR } 1 \text { (pan) e } 4 \text { sat (AS LEIS DE } \\
\text { ESHNUNNA, 1981, p. } 82,85 \text { ). }\end{array}$ \\
\hline $\begin{array}{l}\text { Tomar em penhor (Häböl TaHBöl) } \\
{ }^{22,25} \text { Caso tomares em penhor a roupa do } \\
\text { teu próximo, restituirás a ele antes do } \\
\text { pôr do sol, } \\
{ }_{22,26} \text { porque aquela é a sua cobertura e a } \\
\text { veste da sua pele; em que se deitaria? Por } \\
\text { isso, quando clamar a mim, eu o ouvirei, } \\
\text { porque sou compassivo. }\end{array}$ & \\
\hline $\begin{array}{l}\begin{array}{l}\text { Torcer (desviar) o direito } \\
\text { (taț̣è mišpaț) }\end{array} \\
\text { 23,1 Não espalharás falso boato, e não } \\
\text { porás a tua mão com o ímpio, para seres } \\
\text { testemunha falsa. } \\
{ }_{23,2} \text { Não seguirás a maioria para fazeres } \\
\text { o mal; nem numa demanda falarás, } \\
\text { tomando parte com a maioria para torcer } \\
\text { o direito. } \\
\text { 23,3 Nem ao pequeno favorecerás na sua } \\
\text { demanda. } \\
{ }_{23,6} \text { Não torcerás o direito do teu pobre } \\
\text { na sua demanda. } \\
{ }_{23,7} \text { De palavras de falsidade te afastarás, } \\
\text { e não matarás o inocente e o justo; pois } \\
\text { não justificarei o ímpio. } \\
23,8 \text { Não aceitarás presente [suborno]; } \\
\text { porque o presente cega os que têm vista, } \\
\text { e perverte as palavras dos justos. }\end{array}$ & $\begin{array}{l}\text { Torcer (desviar) o direito } \\
\text { § 1: Se um awīlum acusou um (outro) awīlum e lançou sobre ele (suspeita de) } \\
\text { morte mas não pôde comprovar: o seu acusador será morto. } \\
\text { § 3: Se um awīlum apresentou-se em um processo com um testemunho falso e não } \\
\text { pôde comprovar o que disse: se esse processo é um processo capital esse awīlum } \\
\text { será morto. } \\
\text { § 4: Se se apresentou com um testemunho (falso e causa) de grão ou de prata: ele } \\
\text { carregará a pena desse processo. } \\
\text { § 5: Se um juiz julgou uma causa, deu uma sentença e mandou exarar um documento } \\
\text { selado e depois alterou o seu julgamento: comprovarão contra esse juiz a alteração } \\
\text { do julgamento feito e ele pagará até doze vezes a quantia que estava em questão } \\
\text { nesse processo; além disso fá-lo-ão levantar-se de seu trono de juz na assembleia } \\
\text { e não tornará a sentar-se com os juízes em um processo (HAMMURABI, 1976, } \\
\text { p. 25, 26). }\end{array}$ \\
\hline
\end{tabular}


Não por nada, o estrangeiro vem sempre unido à viúva e ao órfão como paradigmas de pessoas pobres, indefesas e frágeis da sociedade israelita.

Em geral, naqueles tempos, os motivos que levavam uma pessoa ou família a deixar sua terra eram, fundamentalmente: calamidades de fome ${ }^{12}$ e/ou guerra. ${ }^{13}$ Agora, o direito mesopotâmico não registra nada semelhante a Israel em sua preocupação pela garantia dos direitos do estrangeiro residente. Assim, o estrangeiro é alguém sem direitos, por completo. $\mathrm{O}$ que mais impacta e chama a atenção em Ex 22,20.22 e Ex 23,9 "é a alusão ao Egito..., quando evoca a resposta de Deus ao clamor dos israelitas escravos. Aliás, em Ex 23,9 é de se notar o uso do substantivo nepeš: "Ao estrangeiro não oprimirás, porque vós conheceis a vida (respiração, o ritmo de vida) do estrangeiro, pois fostes estrangeiros no Egito". Esse substantivo "designando primitivamente a respiração, parece fazer alusão ao ritmo físico do trabalho e do descanso: trata-se de permitir ao estrangeiro retomar o fôlego" (EPSZTEIN, 1979, p. 547). A experiência histórica de ter sido estrangeiros deve servir de critério para colocar-se no lugar do outro [...]" (ANDIÑACH, 2006, p. 365). O texto usa a expressão não $o$ oprimirás, em relação ao estrangeiro. Isso "porque foi dito acima que foi particularmente opressão que os israelitas foram obrigados a suportar no Egito" (CASSUTO, 2005, p. 291), basta verificar Ex 3,9 e comparar com Ex 23,9; Lv 19,34 e Dt 10,19.

Esse gêr poderia referir-se não somente àquelas pessoas de lugares distantes que habitavam em Israel, mas também os irmãos do norte, da Samaria, que tinham sido vítimas da invasão assíria. Isso, no caso de assumirmos que as leis apodíticas do Código da Aliança tenham sua inspiração na atuação e escritos proféticos do Reino do Norte como propõe, sobretudo, Amós, Oseias, Isaías, Miqueias), entre outros (cf. ARTUS, 2005, p. 128-138).

\section{Leis sobre a viúva e o órfão}

A viúva e o órfão necessitam de proteção porque falta-lhes o amparo do marido e do pai, assim como ao estrangeiro falta a proteção de seu clã por ele encontrar-se fora de seu território. O texto bíblico deixa claro que: “A ausência de um protetor humano da viúva e do órfão não deve iludir os inescrupulosos ou a sociedade que os tolera. O próprio Deus defende a causa dos oprimidos" (SARNA, 1991, p. 138). ${ }^{14}$

\footnotetext{
12 Cf. para os patriarcas de Israel: Gn 12,10; 26,3; 47,4; Rt 1,1; 2Rs 8,1

13 Cf. $2 \mathrm{Sm} \mathrm{4,3}$; Is 16,4 .

14 Cf. Pr 22,22-23; 23,10-11.
} 
Percebe-se uma nítida diferença entre a legislação do Código da Aliança e aquela da Mesopotâmia. Enquanto esta última preocupa-se mais com a casuística dos bens da viúva, sua casa e seus pertences, a legislação israelita é mais ampla, não casuística e embasada em uma forte fórmula de juramento (CASSUTO, 2005, p. 292): "Caso de algum modo os afligires, e eles clamarem a mim, eu certamente ouvirei o seu clamor" (Ex 22,22). Nesse sentido, há uma clara referência à atitude de Deus em relação aos israelitas oprimidos no Egito, cujos clamores são ouvidos pelo Senhor (Ex $3,7)$. No entanto, a legislação israelita não transcura dos detalhes da vida de uma viúva, assegurando-lhe as seguintes prerrogativas (BERGMANN, 1997, p. 520):

- A possibilidade de livrar-se da vergonha de ter permanecido sem filhos, através da prática do levirato: o cunhado lhe comprava o patrimônio do irmão morto, esposava-a e o primeiro filho desta nova relação era considerado filho do defunto marido e levava o seu nome (Dt 25,5-10; p. ex. Gn 38; Rt 4).

- A proteção contra golpes ou penhoramento dos bens (Dt 24,17).

- O sustentamento mediante o dízimo dos proventos recolhidos ao final de cada triênio (Dt 14,28-29), a participação na Festa das Semanas e na Festa das Cabanas (Dt 16,11.14) e o direito à colheita (Dt 24,19ss cf. Rt 2).

O órfão é objeto de uma proteção semelhante para que não passe necessidades (cf. Dt 10,18; 24,19-21; 27,19; S1 68,5; 146,9; Pr 23,10-11).

Fica claro que as pessoas desprotegias deverão ser "resguardadas do ataque e da violência dos poderosos" (SCHWANTES, 2013, p. 48). Essa parece ser uma preocupação comum no Oriente Médio Antigo. O grito, o clamor dos fracos expresso em Ex 22,22 (“eles clamarem a mim"), pode ser entendido como um "apelo à proteção legal" (cf. SCHWANTES, 2013, p. 280). Portanto, uma reinvindicação justa por parte dos débeis que não ficará sem resposta. Nesse sentido, a legislação israelita distingue-se pela teologização da lei.

\section{Leis sobre empréstimos}

Na antiga Mesopotâmia, no tempo de Hammurabi, já existia um mercado ativo de títulos dados em empréstimo, portanto, um incipiente mercado financeiro. Em 1769 a.C., um homem chamado Dumuzi-Gamil pegou 250 gramas de prata emprestados de um vizinho. Prometeu devolver o metal cinco anos depois com juros de 3,78\% ao ano. Parte da prata Dumuzi-Gamil investiu em padarias que forneciam alimentos para o templo de Ur. O que restou ele destinou a pequenos empréstimos a pescadores 
e agricultores, cobrando juros de $20 \%$ ao mês. Era comum agricultores verem o estoque de grãos acabar antes de chegar a hora da colheita, por isso precisavam ficar algumas semanas no "cheque especial".

O prazo do empréstimo de prata de Dumuzi-Gamil era de cinco anos; a taxa de juros estipulada por lei para a prata era de $20 \%$. Isso parece muito pesado. Mas o custo da obtenção de empréstimos era calculado de maneira diferente naquela época. Podia não ser permitido que as taxas variassem competitivamente, mas, dado que elas incidiam sobre todo o prazo da dívida, em vez de serem calculadas anualmente variar a data de quitação alterava a taxa anual equivalente. Os juros de $20 \%$ em cinco anos, como no caso de Dumuzi-Gamil, são o mesmo que pouco mais de $3 \%$ ao ano, o que é muito mais razoável. Se o mesmo percentual fosse cobrado em dois anos, equivaleria a pouco menos de $10 \%$ anuais. Os registros de Dumuzi-Gamil mostram que, quando ele concedia empréstimos a trabalhadores e artesãos, a data de quitação costumava ser um ou dois meses depois. Num prazo tão curto, a taxa de juros equivalia a mais de $800 \%$ ao ano: bastante compensadora para quem emprestava, mas absolutamente incapacitante para o devedor (KRIWACZEK, 2018, p. 237-238).

Portanto, os juros faziam parte do sistema econômico babilônico e a lei os regulava, mas não os coibia. O contrário se passa na legislação do Código da Aliança. Segundo Ex 22,24, era proibido emprestar a juros (usura: nešek) ao pobre, sobretudo. A cobrança de juros a quem, objetivamente não teria condição de pagá-los "é uma forma de conduzi-lo à escravidão contra a sua vontade" (ANDIÑACH, 2006, p. 366). Inclusive, em Dt 23,20ss; Ez 18,8.17; 22,12; S1 15,5 as proibições de cobrar juros valem para todo o povo. E Lv 25,35-38 relaciona essa proibição e os pobres. A expressão 'ammî (meu povo) dá a entender que "o povo oprimido é povo de Deus" (SCHWANTES, 2013, p. 70). As relações nessa sociedade devem ser marcadas não tanto pelo aspecto comercial, como na Mesopotâmia, mas pela atitude de fraternidade, solidariedade, familiaridade. E o jogo de palavras entre: ‘ammî (meu povo) e ‘immäk • (contigo) enfatiza a proximidade do credor ao devedor, são irmãos e não estranhos (CASSUTO, 2005 , p. 292). A preservação da autonomia do mais fraco, do pobre é que está em jogo aqui. Fica claro que a cobrança de juros "era, portanto, uma questão moral, não econômica - assim como fugir da responsabilidade para com os companheiros israelitas e tirar proveito da miséria alheia" (SARNA, 1991, p. 138).

Apesar disso, vários textos bíblicos atestam que houve tempos em que esse ideal foi ignorado pela sociedade: $1 \mathrm{Sm} 22,2 ; 2 \mathrm{Rs} 4,1$; Is 50,$2 ; \mathrm{Jr}$ 15,10; Ez 18,8; 13, 17; 22,12; Am 2,8; S1 109,11; Pr 28,8 e Ne 5,1-13. No entanto, a tradição rabínica enxerga nessa proposição 'im-Kesep Tal•wè 
(Se/caso emprestares dinheiro) não algo opcional, mas obrigatório: "R. Ismael diz: Todos e cada um dos 'se' que há na Torá se referem a um ato voluntário, exceto este e outros dois: E se ofereceres a Yhwh uma oblação de primícias (Lv 2,14), se refere a um ato obrigatório" (MEKILTA DE RABBÍ ISMAEL, Kaspa' I, 1995, p. 427). Outro famoso comentário rabínico ao livro de Êxodo, faz um paralelo entre duas palavras da mesma raíz: $n s ̌ k$ (substantivo: nešek = juros) e $n \check{s} k$ (verbo: nāšak = morder) para daí concluir que: "É uma usura [nešek]. E é como a mordida [nāšak]de uma serpente que morde uma pessoa provocando-lhe uma ferida no pé que não se nota, mas que, de repente, ferve e se difunde para todo o corpo até o cérebro. Assim é a usura: não se percebe nem se nota até que os juros sobem e consomem um grande capital" (RASHI DI TROYES, 1988, p. 203). Palavras sábias e oportunas, até mesmo, para os tempos atuais.

\section{Leis sobre o penhor}

Temos aqui uma decorrência daquilo que foi estabelecido pelo princípio presente no versículo anterior (Ex 22,24). A lei israelita permitia o penhor como uma garantia, mas sob certas condições: Dt 24,17; Am 2,8; Jó 22,$6 ; 24,3$; Pr 20,16. Estas citações referem-se ao abuso de viúvas, estrangeiros, pobres e órfãos por meio de objetos penhorados deles. É evidente que "Ao forçar um credor a restituir as roupas de um pobre todas as noites, isso prejudicou a prática pelo simples inconveniente" (CHILDS, 1974, p. 479). Reconhece-se que o pobre, neste caso, não possui senão sua capa, seu manto $(\mathrm{Sal} \bullet \mathrm{mat})$, portanto, trata-se de alguém miserável, desprovido de qualquer segurança. Essa capa refere-se a um grande pedaço de pano enrolado no corpo. Para os pobres, também servia de cobertor à noite. A prática de pegar vestimentas como penhor é atestada em textos como Am 2,8; Pr 20,16; 27,13 e Jó 22,6. Há, inclusive uma inscrição descoberta em uma fortaleza israelita próxima à Yaveneh-Yam (15 quilômetros ao sul de Tel Aviv, na costa do mar Mediterrâneo, possivelmente ocupada no séc. VII a.C., no tempo do rei Josias de Judá), que testemunha essa prática. Essa inscrição registra "a queixa de um trabalhador agrícola de que o oficial responsável estava retendo sua roupa enquanto aguardava a satisfação de uma reclamação contestada de que o trabalhador não havia cumprido suas obrigações" (SARNA, 1991, p. 139).

É significativa a promessa e confissão de Deus ao final dessa unidade (Ex 22,26): "quando clamar a mim, eu o ouvirei, porque sou compassivo". Essa confissão de YHWH "sou compassivo" (Hannûn 'äonî) "pode ser entendida como a explicação fundamental de todos os mandamentos e "prin- 
cípios orientadores' relacionados aos membros indefesos da comunidade da aliança” (DURHAM, 1987, p. 329). Essa expressão aparece treze vezes no AT usada somente em relação a YHWH. A omissão, extraordinária, do vocábulo "misericordioso" ( $\mathrm{ra}[\mathrm{H}] \mathrm{Hum})$ que sempre acompanha o atributo divino "compassivo" (Hannûn), "talvez ressalte o ponto em que o pobre tem direito à restituição de sua roupa por direito, não como um ato de misericórdia" (SARNA, 1991, p. 140). Mais uma vez, Deus se põe como o garante do cumprimento da justiça em relação ao pobre.

Não há paralelo na legislação do Oriente Médio Antigo. Essa questão não mereceu a atenção dos legisladores e governantes da época. Isso coloca mais em evidência a preocupação social do Código da Aliança.

\section{Leis sobre distorcer a Justiça}

Interessante constatar que o conjunto de leis relativas à vida cotidiana social conclui-se com um grupo de normas dedicadas ao âmbito judicial. Esses ordenamentos afetam tanto os juízes como as testemunhas. Assim, ambos parecem ser os seus destinatários. Os vv. 4-5 de Ex 23 ficaram de fora (cf. tabela acima), pois destoam do conjunto na forma e no conteúdo. Provavelmente, "estariam melhor localizadas na coleção 21,28-35, junto às leis relativas aos bois. [...] Talvez, estejam aqui devido ao complexo processo de redação, que as vinculou por razões históricas ou porque provinham de um mesmo código" (ANDIÑACH, 2006, p. 368).

Em Ex 23,1-3, o primeiro bloco, temos cinco proibições que coíbem o comportamento que colocaria em risco, nos tribunais, a integridade e a imparcialidade do processo judicial:

a) trata dos litigantes, das testemunhas e, por implicação, também do juiz. É proibido e inadmissível prestar testemunhos sem fundamento em processos judiciais.

b) A segunda cláusula (Ex 23,2) proíbe conluio por parte de uma testemunha com uma das partes para fins fraudulentos. Aqui no caso, o termo rabbîm significa, comumente, muitos, maioria. Mas há uma ocorrência em Jó 35,9 com o sentido de poderosos. Caso seguirmos esta última interpretação, "o sentido da lei adquire um valor muito mais forte de solidariedade com os pobres e desprotegidos. É evidente que a tendência a favorecer os ricos existiu em todas as épocas e que era obrigação dos juízes e testemunhas manter a objetividade nos litígios" (ANDIÑACH, 2006, p. 369). 
c) No interesse da justiça imparcial, nenhum privilégio deve ser dado à posição social dos litigantes.

d) Em sequência, há uma advertência para não perverter a justiça, aderindo à visão da maioria, se alguém estiver convencido de que é errado.

e) A frequência com que a Torá exige compaixão pelos pobres determina a necessidade de cautela a fim de evitar que as emoções, por mais desejáveis e nobres que sejam, turve o próprio julgamento.

É de se notar a ocorrência do termo däl ("pequeno") ao se referir ao pobre, ao fraco socialmente falando. O uso é semelhante a Lv 19,15:

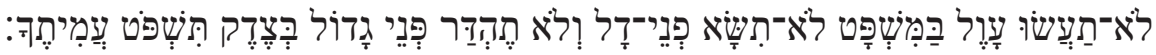

Em uma tradução bem literal, teríamos: "Não fareis injustiça no juízo, nem privilegiarás (lit.: erguerás as faces) do pequeno, nem tratarás com distinção o (lit.: as faces do) grande; com justiça julgarás o teu compatriota". Aqui, a escolha de däl (pequeno) é proposital, no sentido de contrastar melhor com gädôl (grande), sendo que o sentido de ambos os termos é metafórico: o pequeno sendo o pobre, o fraco; e o grande sendo o poderoso, o rico o forte na sociedade. Em Ex 23,3, temos o mesmo verbo (teh•Dar) de Lv 19,15, mas com outro objeto, o "pequeno":

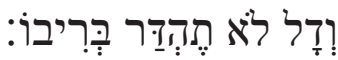

A tradução mais literal possível poderia ser: "E o pequeno não tratarás com distinção em sua demanda/contenda". Com isso, tanto Lv 19,15 como Ex 23,3 buscam evitar que a justiça seja parcial, privilegiando, de algum modo, uma das partes em contenda (cf. SCHWANTES, 2013, p. 60-62). No entanto, Ex 23,6 reequilibra a questão judicial, fazendo uma forte advertência: "Não torcerás (lit.: afastarás para o lado, desviarás) o direito do teu pobre na sua demanda". Isso porque, obviamente, o pequeno, o pobre têm mais dificuldades em fazer valer a sua causa justa, devido à sua condição econômica e social. Ele não é justo por ser pobre, mas por ter uma demanda justa que precisa ser tratada com equidade por parte das autoridades. Nesse sentido, "Ex 23,6, portanto, não exige um favorecimento incondicional, nenhum status especial para o pobre. A proibição está sob o signo da igualdade de todos no processo! Por esta causa a preterição do fraco deve ser combatida" (SCHWANTES, 2013, p. 66-67). Os pequenos, 
os pobres, os fracos na sociedade israelita poderiam ser aqueles que haviam se tornado escravos para pagarem suas dívidas, pequenos agricultores empobrecidos que mal conseguiam se sustentar, viúvas, órfãos, estrangeiros, enfim, toda uma gama de pessoas para as quais o Código da Aliança dirige um olhar especial.

Segue-se agora outra sequência de três versículos (Ex 23,7-9), que estão ligados pela assonância que marca as palavras finais de seus orações iniciais: Tir•Häq (mantenha-se longe), tiqqäh (tu tomarás, pegarás, aceitarás), til•Häc (tu oprimirás). Observa-se Em Ex 23,8 que "A sintaxe hebraica destaca a gravidade da ofensa colocando 'suborno' [šöHad] na posição inicial enfática. $\mathrm{O}$ texto, aparentemente, cita algum provérbio bem conhecido, repetido quase literalmente em Deuteronômio 16,19" (SARNA, 1991, p. 143).

A legislação de Hammurabi, conforme mostra a tabela acima, tem seus pontos de contato com aquela israelita em dois aspectos principais:

a) a condenação do falso testemunho;

b) a má conduta de juízes que não fazem justiça, mas cedem às tentações de subornos e outras influências.

Evidencia-se na legislação mesopotâmica a frequência com que o falso testemunho vem punido com a pena capital, ou seja, a morte. O Código da Aliança, nesse sentido, não acompanha tal tendência. A justiça é valorizada por si mesma, sem necessidade de uma dura punição, pois é Deus mesmo quem toma posição: "não justificarei o ímpio" (Ex 23,7c). Resta claro de qual lado Deus se coloca: do pobre, do mais fraco, do pequeno e desprotegido.

\section{Conclusão}

O Código da Aliança, não somente ele, mas também a Lei de Santidade (Lv 17,1-26,46) e o Código Deuteronômico (Dt 12,1-26,15), deixam claro que o papel central e o dispensador único da lei é Deus. O papel do rei é menos que secundário, praticamente, ele não aparece. Basta conferir $1 \mathrm{Sm} \mathrm{8,18} \mathrm{e} \mathrm{Dt} \mathrm{17,14-20} \mathrm{para} \mathrm{nos} \mathrm{darmos} \mathrm{conta} \mathrm{que} \mathrm{não} \mathrm{há} \mathrm{nenhuma} \mathrm{alusão}$ ao poder real. Pelo contrário, o texto de Sm adverte contra as arbitrariedades que o rei, certamente, cometerá; e o texto de Dt intima o rei a ter uma cópia da lei divina para observá-la estritamente. O fato de Deus dirigir-se ao povo, nos códigos legais da Torá, pelo pronome "tu", já indica que ele se dirige a todo o povo e a cada pessoa em particular. Pela vontade de 
Deus toda a sociedade se torna "depositária da lei e responsável quanto ao seu respeito e aplicação. Todo indivíduo que faz parte da comunidade é envolvido. As leis ditadas por Deus não se limitam a uma circulação vertical, ou seja, de Deus aos fiéis, mas se propagam também na horizontal, de uma forma democrática, de pessoa a pessoa" (EPSZTEIN, 1979, p. 535).

Outra característica própria da legislação israelita é a motivação que se encontra na busca da justiça. Nos "códigos" mesopotâmicos a motivação de se buscar a justiça é a prosperidade e o bem-estar, acima de tudo. Vejamos umas partes do prólogo do "código" de Hammurabi:

Eu sou Hammurabi, o pastor, chamado por Enlil, aquele que acumula opulência e prosperidade, aquele que realiza todas as coisas para Nippur, DUR.AN. [...]

Quando o deus Marduk encarregou-me de fazer justiça aos povos, de ensinar o bom caminho ao país, eu estabeleci a verdade e o direito na linguagem do país, eu promovi o bem-estar do povo (HAMMURABI, 1976, p. 20, 24).

O prólogo do "código" de Lipit-Ishtar, também, segue nesse mesmo sentido. Vejamos:

Quando An o Grande, o pai dos deuses, e Enlil, o rei de todos os países, o senhor que estabelece os destinos, tinham dado um reino favorável e a realeza sobre Sumer e Acad em Isin, o pedestal que An lhe estabeleceu, em Nininsina, a filha de An, a Senhora humilde, de cuja autoridade nos alegramos e para cuja testa luminosa nos voltamos (?), quando então An e Enlil tinham chamado à soberania sobre o país Lipit-Ishtar, o pastor obediente, nomeado por Nunamnir, para estabelecer a justiça no país, para fazer desaparecer o lamento da boca, para afastar a maldade e a violência, para buscar o bem-estar a Sumer e Acad, então eu, Lipit-Ishtar, o pastor humilde de Nippur [...] (SEUX, 1990, p. 513).

Ainda que, em Israel, esse tipo de interesse não seja totalmente excluído (cf. Dt 6,18), o que predomina é a busca da justiça por si mesma. Como fica claro em Dt 16,20: “A justiça, somente a justiça perseguirás, para que vivas e possuas a terra que YHWH, teu Deus, te dá”. Por isso, a busca da imparcialidade e uma justiça especial para os pobres e fracos juridicamente da sociedade constituem-se na marca característica de sua legislação.

À diferença da lei de Hammurabi inscrita em uma grande estela com a finalidade de honrar o rei e a sua "bondade", os códigos de YHWH devem estar gravados e inscritos no coração de cada pessoa, de cada fiel: "Mas esta é a aliança que farei com a casa de Israel depois daqueles dias, diz YHWH: porei a minha lei no seu interior e a escreverei no seu coração; e eu serei o seu Deus, e eles serão o meu povo" (Jr 31,33). Não 
é uma lei para estar fixada em um lugar, mas para se levar onde quer que se vá. O direito divino de Israel é itinerante, assim como o povo pelo deserto. É uma lei que não depende de território, mas da adesão de cada pessoa.

Finalmente, é de se destacar que a justificativa para se evitar todo tipo de injustiça e opressão (maus tratos, discriminações etc.) aos demais membros da sociedade é o fato do próprio povo de Israel ter experimentado tudo isso em sua própria pele, enquanto estava no Egito (cf. Ex 22,20; 23,9 - para ficarmos somente no Código da Aliança). Aqui consiste, portanto, na perspectiva das narrativas legislativas do assim chamado Código da Aliança, o motivo pelo qual entendemos que o pobre tem vez.

\section{Referências bibliográficas}

ANDIÑACH, Pablo R. El libro del Éxodo. Salamanca: Sígueme, 2006. (Biblioteca de Estudios Bíblicos, 119).

ARTUS, Olivier. Les lois du Pentateuque: points de repère pour une lecture exégétique et théologique. Paris: Les Édition du Cerf, 2005. (Lectio Divina, 200).

AS LEIS DE ESHNUNNA. Introdução, texto cuneiforme em transcrição, tradução e comentário de Emanuel Bouzon. Petrópolis: Vozes, 1981. (Textos Clássicos do Pensamento Humano, 5).

BERGMANN, H. Vedova. In: BURKHARDT, H. et alii. Grande enciclopedia illustrata della Bibbia. Volume 3: Pacat-Moab - Zorobabele. Trad. Monache Benedettine di Marinasco. Casale Monferrato, AL: Piemme, 1997, p. 520-521.

BÍBLIA DE JERUSALÉM. Nova edição, rev. ampl. Trad. Euclides Martins Balancin et alii. São Paulo: Paulus, 2002.

BRANCH, Robin G.; WILSON, Marvin R. Widows \& Orphans. In: YAMAUCHI, Edwin M.; WILSON, Marvin R. Dictionary of daily life in biblical and post-biblical antiquity. Peabody, MA: Hendrickson, 2017, p. 1742-1760.

CASSUTO, Umberto Moshe David. A commentary on the book of Exodus. Trad. Israel Abrahams. Skokie, IL: Varda Books, 2005.

CHILDS, Brevard S. The book of Exodus: a critical, theological commentary. Louisville, KY: The Westminster John Knox Press, 1974. (The Old Testament Library).

CRÜSEMANN, Frank. A Torá: teologia e história social da lei do Antigo Testamento. Trad. Haroldo Reimer. Petrópolis: Vozes, 2002.

DURHAM, John I. Exodus. Waco, TX: Word Books, 1987. (Word Biblical Commentary, 3).

ELLIGER, Karl; RUDOLPH, Wilhelm (Hrsg.). Biblia Hebraica Stuttgartensia. 4. verb. aufl. Stuttgart: Deutsche Bibelgesellschaft, 1990. 
EPSZTEIN, Léon. Les lois sociales du Pentateuque. Revue Historique de Droit Français et Étranger, Paris, v. 57, p. 531-567, 1979.

GRENZER, Matthias. O projeto do Exxodo. São Paulo: Paulinas, 2004. (Coleção Bíblia e História).

HALBE, Jörn. Das Privilegrecht Jahwes Ex 34,10-26: Gestalt und Wesen, Herkunft und Wirken in vordeuteronomischer Zeit. Göttingen: Vandenhoeck \& Ruprecht, 1975. (Forschungen zur Religion und Liberatur des Alten und Neuen Testaments, 114).

HALLO, William W.; YOUNGER, JR., K. Lawson. The context of Scripture. Volume I: Canonical compositions from the biblical world. Leiden; Boston: Brill, 2003.

HALLO, William W.; YOUNGER, JR., K. The context of Scripture. Volume II: Monumental inscriptions from the biblical world. Leiden; Boston: Brill, 2003.

HAMMURABI, REI DA BABILÔNIA. O código de Hammurabi. Trad. intr. com. Emanuel Bouzon. 2. ed. Petrópolis: Vozes, 1976. (Textos Clássicos do Pensamento Humano, 4).

JOHNSTON, David. Breve história da justiça. Trad. Fernando Santos. São Paulo: WMF Martins Fontes, 2018.

KRIWACZEK, Paul. Babilônia: a Mesopotâmia e o nascimento da civilização. Trad. Vera Ribeiro. Rio de Janeiro: Zahar, 2018.

LASSERRE, Guy. Quelques études récentes sur le Code de l'Alliance. Revue de Théologie et de Philosophie, Genève, v. 125, n. 3, p. 267-276, 1993.

MEKILTA DE RABBÍ ISMAEL. Comentario rabínico al libro del Éxodo. Trad. Teresa Martínez Sáiz. Estella: Editorial Verbo Divino, 1995. (Biblioteca Midrásica, 16).

OOSTHUIZEN, M. J. Law and theology in the Covenant Code. Skrif en Kerk, Pretoria, v. 17 , n. 1, p. 160-190, 1996.

OTTO, Eckart. A lei de Moisés. Trad. Monika Otterman. São Paulo: Loyola, 2011. (Bíblica Loyola, 61).

RASHI DI TROYES. Commento all'Esodo. A cura di Sergio J. Sierra. Genova; Milano: Marietti, 1988. («Ascolta, Israele!» Commenti alle Scritture delle tradizioni hebraica e Cristiana, 5).

RENAUD, Bernard. L'alliance au coeur de la Torah. Paris: Service Biblique Catholique Évangile et Vie; Les Édition du Cerf, mars 2008. (Cahiers Évangile, 143).

SARNA, Nahum M. Exodus: the traditional text with the new JPS translation. Philadelphia; New York; Jerusalem: The Jewish Publication Society, 1991. (The JPS Torah Commentary).

SCHWANTES, Milton. O direito dos pobres. São Leopoldo: Oikos; São Bernardo do Campo: Editeo, 2013.

SEUX, M.-Joseph. Leggi dell'Antico Oriente. In: VV.AA. L'Antico Testamento e le culture del tempo: testi scelti. Trad. Carlo Valentino. Roma: Borla, 1990, p. 499-605. 
SKA, Jean-Louis. O direito de Israel no Antigo Testamento. In: MIES, Françoise (Org.). Bíblia e direito: o espírito das leis. Trad. Paula S. R. C. Silva. São Paulo: Loyola, 2006, p. 17-46.

VERKINDÈRE, Gérard. La justice dans l'Ancien Testament. Paris: Service Biblique Catholique Évangile et Vie; Les Édition du Cerf, sept. 1998. (Cahiers Évangile, 105).

WIÉNER, Claude. El libro del Exodo. Trad. Nicolás Darrical. 6. ed. Estella: Editorial Verbo Divino, 2000. (Cuadernos Bíblicos, 54).

ZENGER, Erich (Ed.). Introduzione all'Antico Testamento. Trad. Enzo Gatti e Gianni Francesconi. 2. ed. Brescia: Queriniana, 2008.

\section{Notas}

I Para ser mais fiel ao texto hebraico, a tradução é a mais literal possível.

II Essa é a mais antiga menção à proteção do órfão e da viúva. Ela vem da Suméria. Seu autor é o último rei de Lagash (cerca de 2351-2342 a.C.) Uru-iningina, anteriormente conhecido como Uru-kagina: "Ele estabeleceu as primeiras reformas legais na Mesopotâmia. Por causa da situação política das cidades-estados em guerra, os ricos estavam oprimindo os pobres" (BRANCH; WILSON, 2017, p. 1747). O texto acima integra uma inscrição de sua autoria dedicada ao deus de Lagash.

III Esse texto integra o prólogo do código legal de Ur-Nammu (cerca de 2050 a.C.), fundador da III Dinastia Suméria de Ur. Ele se refere ao tratamento especial que viúvas e órfãos receberam durante o seu reinado.

IV Essa identificação do parágrafo é anormal no código de Hammurabi, pois foram raspadas e se tornaram ilegíveis sete colunas (XVII-XXIII) da estela encontrada em Susa. Portanto, há um salto do $\S 65$ até o $§ 100$. Esses parágrafos perdidos foram, em parte, recuperados graças a cópias desse código.

Submetido em: 2-9-2019

Aceito em: 8-11-2019 